\title{
Differential Spread of Grapevine Red Blotch Virus in California and New York Vineyards
}

\author{
Elizabeth Cieniewicz, ${ }^{1, \dagger}$ Madison Flasco, ${ }^{1}$ Melina Brunelli, ${ }^{1,2}$ Anuli Onwumelu, ${ }^{1,3}$ Alice Wise, ${ }^{4}$ \\ and Marc F. Fuchs ${ }^{1}$ \\ ${ }^{1}$ Section of Plant Pathology and Plant-Microbe Biology, School of Integrative Plant Science, Cornell AgriTech, \\ Geneva, NY 14456 \\ ${ }^{2}$ Departments of Chemistry and Biological Sciences, Harpur College of Arts and Sciences, Binghamton University, \\ State University of New York, Binghamton, NY 13902 \\ ${ }^{3}$ Department of Forest and Natural Resources Management, State University of New York, College of \\ Environmental Science and Forestry, Syracuse, NY 13210 \\ ${ }^{4}$ Cornell Cooperative Extension, Long Island Horticultural Research and Extension Center, Riverhead, NY 11901
}

Accepted for publication 24 June 2019.

\section{ABSTRACT}

Limited information is available on the spread dynamics of grapevine red blotch virus (GRBV, genus Grablovirus, family Geminiviridae) in vineyards. In this study, we investigated red blotch disease progress in three vineyards with a disparate initial inoculum prevalence. Secondary spread was documented in Cabernet Sauvignon and Cabernet franc vineyards in California, but not in a Merlot vineyard in New York. Increase in annual disease incidence $(4.8,0.13$, and $0 \%)$ was unrelated to the estimated initial source of inoculum at planting (1, 40, and $40 \%)$ in the Cabernet franc, Cabernet Sauvignon, and Merlot vineyards, respectively. Limited genetic diversity of GRBV populations in newly infected vines supported localized spread in California vineyards, and suggested the planting material as the primary source of inoculum. Among the community of hemipteran insects visiting two of the three study vineyards, populations of Spissistilus festinus, the vector of GRBV, were absent in the Merlot vineyard and low in the Cabernet Sauvignon vineyard. Furthermore, all cover crop samples collected from GRBV-infected California vineyards each spring of 2016 to 2018 , particularly legume species which are preferred hosts of $S$. festinus, tested negative for GRBV, suggesting a minimal role, if any, in GRBV spread as inoculum reservoirs. Together our findings illustrate differential disease progress in distinct vineyard ecosystems, and support the elimination of virus inoculum sources as an actionable disease management strategy across vineyards.

Keywords: agriculture, ecology, ecosystems, entomology, grapevine red blotch, Spissistilus festinus, virology
${ }^{\dagger}$ Corresponding author: E. J. Cieniewicz; ejc238@ cornell.edu

Funding: This work was funded in part by the American Vineyard Foundation, the California Department of Food and Agriculture, the California Grape Rootstock Research Foundation, the California Grape Rootstock Improvement Commission, the New York Wine and Grape Foundation, the U.S. Department of Agriculture-National Institute of Food and Agriculture Hatch project 1004285 and Predoctoral Fellowship award 2018-67011-27995, Federal Capacity Funds, and Cornell AgriTech Research Venture Funds.

*The $e$-Xtra logo stands for "electronic extra" and indicates that one supplementary figure is published online.

The author(s) declare no conflict of interest.

(C) 2019 The American Phytopathological Society
Grapevine red blotch disease was described for the first time in 2008 on Vitis vinifera 'Cabernet Sauvignon' in California (Calvi 2011). Grapevine red blotch virus (GRBV) was initially identified in association with diseased vines (Al Rwahnih et al. 2013; Krenz et al. 2012) and later found to be the causative agent of red blotch disease (Yepes et al. 2018). Grapevine red blotch virus is the type species of the genus Grablovirus in the family Geminiviridae (Varsani et al. 2017). The GRBV genome consists of single-stranded circular DNA with seven putative bidirectional, overlapping open reading frames (Cieniewicz et al. 2017a; Vargas-Asencio et al. 2019). GRBV isolates comprise two distinct phylogenetic clades (Krenz et al. 2014). The biological implications of these two groups of virus genetic variants are unknown.

Red-berried grape cultivars infected with GRBV show symptoms of foliar reddening, similar to those of leafroll disease, mite feeding 
damage, and nutrient deficiencies (Cieniewicz et al. 2017a). Infected white-berried $V$. vinifera cultivars may show chlorosis and cupping, similar to leafroll or magnesium deficiency. Red blotch disease results in delayed ripening and reduced fruit qualities (Blanco-Ulate et al. 2017; Martínez-Lüscher et al. 2019). Economic losses due to red blotch disease are estimated to range from $\$ 2,213$ to $\$ 68,548$ per hectare over the 25 -year lifespan of Cabernet Sauvignon and Merlot vineyards (Ricketts et al. 2017).

Long-distance spread of GRBV is attributed to dissemination of infected planting material. This has resulted in detection of GRBV in viticulture regions of the United States (Krenz et al. 2014) and Canada (Poojari et al. 2017; Xiao et al. 2015). The virus was also described in Switzerland (Reynard et al. 2018), South Korea (Lim et al. 2016), Mexico (Gasperin-Bulbarela et al. 2019), Argentina (Luna et al. 2019), and India (Marwal et al. 2019). A 3-year study of a 2-ha $V$. vinifera 'Cabernet franc' vineyard planted in 2008 in Napa County, California revealed a 1 to $2 \%$ annual increase in disease incidence from 2014 to 2016 (Cieniewicz et al. 2017b). The aggregation of symptomatic vines at the vineyard edge proximal to an unmanaged riparian area surrounding the Napa River combined with randomly isolated symptomatic vines was suggestive of virus spread via a flying insect vector (Cieniewicz et al. 2017b). GRBV was also detected in free-living Vitis spp. in Napa County (Bahder et al. 2016a; Perry et al. 2016), and in high frequency in free-living grapevines close to commercial vineyards throughout northern California (Cieniewicz et al. 2018a), further supporting evidence of GRBV spread by an insect vector. So far, spread of GRBV has been documented in a single epidemic in California (Cieniewicz et al. $2017 \mathrm{~b}$ ), and suggested in vineyards in Oregon by an unknown vector (Dalton et al. 2019).

An insect study in the area of the Cabernet franc vineyard in Napa County, California, where secondary spread of GRBV was first documented (Cieniewicz et al. 2017b) showed that only 4 of the 43 insect species/taxa caught on sticky cards qualified as potential vector candidates based on at least $30 \%$ of their specimens testing positive for GRBV in PCR (Cieniewicz et al. 2018b). Indeed, GRBV was consistently detected in the three-cornered alfalfa hopper (Spissistilus festinus [Say], Membracidae), Colladonus reductus (Cicadellidae), Osbornellus borealis (Cicadellidae), and a Melanoliarus species (Cixiidae) over two growing seasons (Cieniewicz et al. 2018b). These four hemipteran vector candidates are not typically considered pests of grapevine but are all phloemfeeders (Holzinger et al. 2002; Jensen 1957; Mueller and Dumas 1975; Wolfe 1955; Wolfe et al. 1950). In the same study, only 0 to $8 \%$ of specimens of all the other insect species caught on sticky cards tested positive for GRBV (Cieniewicz et al. 2018b).

Recently, GRBV was shown to be transmitted by $S$. festinus in a greenhouse setting (Bahder et al. 2016b). Noteworthy, a significant association between the spatial distribution of $S$. festinus and GRBV-infected vines was documented in the diseased Cabernet franc vineyard, suggesting that $S$. festinus is likely a vector of epidemiological relevance (Cieniewicz et al. 2018b). This association was not documented with $C$. reductus, $O$. borealis, and a Melanoliarus species (Cieniewicz et al. 2018b). The ability of the latter three insects to transmit GRBV is unknown, and should be tested in future studies. Similarly, other hemipteran insects that ingested GRBV, even at extremely low rates, should be tested in controlled transmission assays for the ability to vector the virus.

Cover crops are often sown between vineyard rows for soil health amendments, erosion control, and natural enemy habitat. Cover crop mixes of legumes, wild flowers, and grasses are commonly used in northern California vineyards. Because S. festinus prefers to feed and reproduce on legumes (Preto et al. 2018a), it is therefore important to assess the potential impact of vineyard cover crops on spread of red blotch by serving as sources of GRBV inoculum in vineyards.

The main objectives of this study were to (i) characterize the spread of GRBV in New York and California vineyards in conjunction with the populations of potential insect vectors, including $S$. festinus, the only vector currently known, and (ii) assess the role of cover crops in red blotch disease epidemiology as potential inoculum reservoirs. We hypothesized an association between GRBV spread dynamics and relative abundance of S. festinus, and a limited role of cover crops as alternative hosts of GRBV.

\section{MATERIALS AND METHODS}

Study vineyard selection in California and New York. Three vineyards, two in California and one in New York, with vines showing red blotch disease symptoms and confirmed presence of GRBV in symptomatic vines by PCR were chosen for this study. In a 2-ha Cabernet franc vineyard in California, we expanded on previous research carried out from 2014 to 2016 (Cieniewicz et al. 2017 b; 2018b) by assessing disease progress in 2017 and 2018. The Cabernet franc vines were grafted onto rootstock 101-14 Mgt (V. riparia $\times V$. rupestris) and planted in 2008. The 1.5-ha V. vinifera 'Cabernet Sauvignon' vineyard in Napa County, California was planted in 2008 with vines derived from two different clones, CS4 and CS169, on the south and north sections of the vineyard, respectively, both grafted onto rootstock 101-14 Mgt. This vineyard was chosen for this study because of (i) its proximity to the 2-ha Cabernet franc vineyard (Fig. 1), and (ii) red blotch symptoms observed in nearly all of the vines derived from clone CS4 in the first year post-planting. A 1.2-ha V. vinifera 'Merlot' clone 181 vineyard planted in 2008 in Suffolk County, New York was also chosen for this study, due to an initial incidence of $40 \%$ of the vines showing foliar reddening symptoms. Merlot vines were also grafted onto 101-14 Mgt.

Survey for GRBV incidence in California and New York vineyards. The two California vineyards were visually surveyed for disease symptoms in October 2017 and 2018. To provide confidence in symptom assessment, a subset of vines was tested for GRBV by PCR in each vineyard. In the Cabernet franc vineyard, leaf and petiole samples (six to eight leaves per vine, four to five from each side of the trunk) from 50 symptomatic and 38 asymptomatic vines were tested for GRBV by PCR with primers targeting a coat protein (CP) gene fragment and a replicaseassociated protein (Rep) gene fragment (Cieniewicz et al. 2017b; Krenz et al. 2014). In the Cabernet Sauvignon vineyard, leaf and petiole samples were similarly collected from a subset of symptomatic vines of clone $4(n=12$ in October 2017 and $n=24$ in October 2018) and clone $169(n=22$ in October 2017 and $n=7$ in October 2018). In 2017, samples were collected from any vines in the Cabernet Sauvignon clone 169 showing any red leaf symptoms. Any of the symptomatic clone 169 vines testing negative for GRBV were then tested for grapevine leafroll virus-1, $-2,-3$, and -4 by enzyme-linked immunosorbent assay using commercial antibodies (Bioreba AG, Reinach, Switzerland). PCRs were carried out using HotStar Taq (Qiagen, Hilden, Germany) at manufacturer-suggested conditions in a C1000-touch Thermocycler (Bio-Rad, Hercules, CA). DNA amplicons were resolved by electrophoresis on $2 \%$ agarose gels in $1 \times$ Tris-acetate-EDTA buffer and then stained with GelRED (Biotium, Fremont, CA).

The New York vineyard was not surveyed for visual red blotch disease symptoms. This is because aggressive leaf removal in the fruiting zone postvéraison by the vineyard manager confounded symptomatology of infected vines. Instead, leaf and petiole samples ( six to eight leaves per vine, three to four from each side of the 
trunk) were collected from 65 vines in late August or September of each year from 2014 to 2016. In 2017 and 2018, samples were collected from only those vines that tested negative for GRBV in the previous years.

Genetic diversity of GRBV isolates from infected grapevines. Total DNA was isolated from symptomatic grapevines in study vineyards using the H.P. Plant DNA kit (OMEGA Biotek, Norcross, GA) and tested for GRBV. To determine genetic relatedness of GRBV isolates from infected vines in the New York vineyard and the Cabernet Sauvignon vineyard in California, a 750-bp fragment spanning the GRBV origin of replication was amplified by PCR using primers GRBVdivFOR (5' GAGGGTATGTGAGGA AGAAG $3^{\prime}$ ) and GRBVdivREV (5' GCAGAAGGCAACGATA TATCC $3^{\prime}$ ) (Perry et al. 2016). PCR products were then purified using ExoSAP-IT (Applied Biosystems, Foster City, CA) and Sanger-sequenced at the Cornell University Biotechnology Resource Center (Ithaca, NY). Sequences were assembled using the Lasergene software suite (version 15.1.1) and aligned using ClustalW (Thompson et al. 1994). Phylogenies were constructed considering 575 nucleotides of the GRBV isolates characterized in this study and others for which sequence information is available in GenBank using the neighbor-joining method (Saitou and Nei 1987). Branching confidence was estimated using 1,000 bootstrap replicates.

Insect survey, handling, and GRBV detection. An insect survey was conducted in the Cabernet Sauvignon vineyard in Napa County, California from March to November 2017 and 2018. Sticky cards were placed in 12 rows, in alternating panels (area between trellis posts) spanning six four-vine panels per row so that each row contained three sticky cards. Each sticky card was collected and replaced with a new sticky card in the adjacent panel each week, so that sticky cards were switched from A-C-E orientation to B-D-F orientation each week, alternating the panel in every other row so that a checkerboard-like pattern was achieved (Cieniewicz et al. $2018 b$ ). The vineyard area surveyed for insects included six rows of clone CS4 and six rows of clone CS169. Sticky cards were shipped weekly to the laboratory in Geneva, New York.

An insect survey was also conducted in the Merlot vineyard in Suffolk County, New York. A total of 52 yellow sticky cards was placed on the lower catch wire throughout the vineyard in five rows, with one trap in alternate panels of six vines, from April through August 2017 and 2018. Traps were collected every 2 weeks, placed in clear plastic bags and shipped to the laboratory in Geneva, New York.

Hemipteran insects caught on sticky cards were identified based on morphological characteristics to the genus and species level when possible with the expert assistance of Greg Loeb (Department of Entomology, Cornell University). Also, the identity of the vector candidates previously identified, i.e., S. festinus, C. reductus, $O$. borealis, and a Melanoliarus species, was characterized by mitochondrial cytochrome $\mathrm{C}$ oxidase gene I (COI) barcode-based sequencing (Cieniewicz et al. 2018b). Insect surveys focused on hemiptera because no other insects were found ingesting GRBV in a previous study (Cieniewicz et al. 2018b). The number of each specimen was recorded prior to their removal from the sticky card to identify relative abundance and diversity. A subset of specimens of high abundance ( $>60$ during a growing season) were chosen at random to be tested for GRBV by multiplex PCR, and those of low abundance $(<60)$ were all tested. Specimens of $S$. festinus and insect species that were previously identified as vector candidates, i.e., C. reductus, O. borealis, and a Melanoliarus species (Cieniewicz et al. 2018b), were all tested, with the exception of $C$. reductus in 2017. Removal of individual specimens from the yellow sticky cards was facilitated using Goo Gone liquid degreaser (Weiman Products, Gurnee, IL) to dissolve adhesive. Individual specimens were stored in microcentrifuge tubes at $-20^{\circ} \mathrm{C}$ until testing.

To test the ability of insects removed from the sticky cards at ingesting GRBV, total DNA was extracted from individual specimens using the E.Z.N.A. Insect DNA Kit (OMEGA Biotek) and stored at $-20^{\circ} \mathrm{C}$. Specimens were tested for GRBV using multiplex PCR. Detection of GRBV in specimens was assumed to be a result of virus ingestion.

Survey for GRBV in vineyard cover crop species. In order to investigate whether cover crops in vineyards serve as alternative GRBV inoculum source, cover crop samples were collected in 13 vineyards of cultivars Petit Verdot, Cabernet Sauvignon, Cabernet franc, and Sauvignon blanc in Napa County, California. These vineyards reflected a variety of cultivars, levels of red blotch disease pressure (high to low), and terrains on a single 620-ha estate.

Cover crops were collected for GRBV testing each April/May from 2016 to 2018 prior to tilling or mowing of the cover crops. Samples were collected from two to four quadrats $(6 \mathrm{~m} \times 2 \mathrm{~m}$ within a single row) in each vineyard. Samples from each quadrat were pooled together in $11 \times 13$ inch plastic bags. Samples were shipped overnight to the laboratory in Geneva, New York for testing. Each bag was subsampled to separate cover crop species. In 2016 and 2017, DNA was extracted from petioles and stems of 5 to 20 plants of a given cover crop species using the H.P. Plant DNA kit (OMEGA Biotek). In 2018, total nucleic acids were isolated using the Kingfisher Flex Magnetic Particle Processor (Thermo Fisher Scientific, Waltham, MA) and the MAGMAX 96 Viral RNA

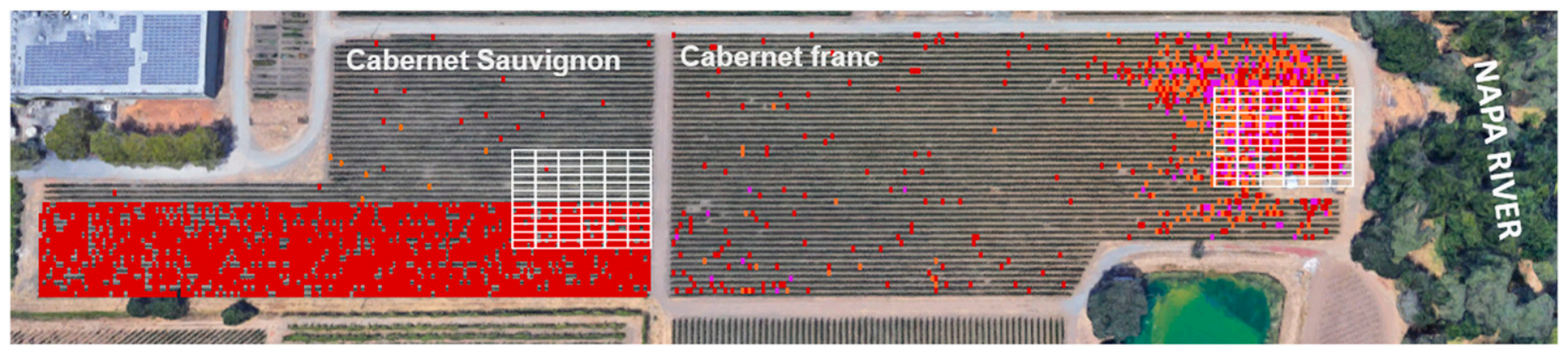

Fig. 1. Map illustrating two red blotch disease epidemics in a 1.5-ha Cabernet Sauvignon and a 2.0-ha Cabernet franc vineyard within 10 years postplanting in California, and the proximity of these vineyards to the Napa River and riparian habitat. In the Cabernet Sauvignon vineyard, red overlay indicates diseased vines in 2017 at the onset of the study and orange indicates new GRBV infections in 2018. In the Cabernet franc vineyard, red overlay indicates initial disease incidence recorded previously for 2014 to 2016 (Cieniewicz et al. 2017a). Purple and orange indicate new infections in 2017 and 2018, respectively. White grids indicate areas where insect survey was conducted in 2015 and 2016 in the Cabernet franc (Cieniewicz et al. 2018b) and in 2017 and 2018 in the Cabernet Sauvignon (this study). 
isolation kit (Life Technologies, Carlsbad, CA). Samples were tested for GRBV using multiplex PCR.

\section{RESULTS}

Secondary spread of GRBV in California and New York vineyards. Disease incidence in the 2-ha Cabernet franc vineyard in California increased from 9\% (696 of 7,691 vines diseased) in 2017 to $13.8 \%$ (1,058 of 7,691 vines diseased) in 2018. Testing of 50 symptomatic vines and 38 asymptomatic vines in the Cabernet franc vineyard in 2018 for GRBV by multiplex PCR demonstrated a $100 \%$ correlation between symptoms and infection status.

In the adjacent 1.5-ha Cabernet Sauvignon vineyard in California, disease symptoms were widespread throughout vines of clone 4 by 1 to 2 years post-planting. This suggested that the inoculum originated from the planting material, particularly from the scion because disease symptoms were noticeable soon after vines were established in the vineyard. Based on visual assessment, red blotch symptoms were apparent in very few $(<15)$ vines throughout clone 169 in the years between planting in 2008 and our survey in 2017 (Fig. 2). Testing of symptomatic vines of clone 169 demonstrated 17 of 22 vines infected in 2017, as shown by PCR. Three of the five vines of clone 169 that tested negative for GRBV in 2017 tested positive for grapevine leafroll-associated virus-3. In 2018, 7 of 7 newly symptomatic vines tested positive for GRBV. In the vineyard section established with clone 169, disease incidence increased from $0.61 \%$ (17 of 2,799 vines diseased and GRBVpositive by PCR) in 2017 to $0.86 \%$ ( 24 of 2,799 vines diseased and GRBV-positive by PCR) in 2018. This result was consistent with limited spread of GRBV in vines of clone 169 despite the availability of a large initial source of inoculum (estimated $40 \%$ at planting), confined primarily to adjacent vines of clone 4 (Fig. 2).

In the 1.2-ha Merlot vineyard in New York, red blotch disease symptoms were observed in 2009, the year after planting, suggesting introduction of GRBV in the scion. However, disease incidence could not be reliably assessed visually because foliar symptomatology was confounded by extensive leaf removal in the fruiting zone by the vineyard manager at a postvéraison development stage, thereby removing the oldest leaves where foliar red blotch symptoms are pronounced. Although the actual initial disease incidence is unknown, the vineyard manager reported an estimated $40 \%$ disease incidence at planting based on foliar
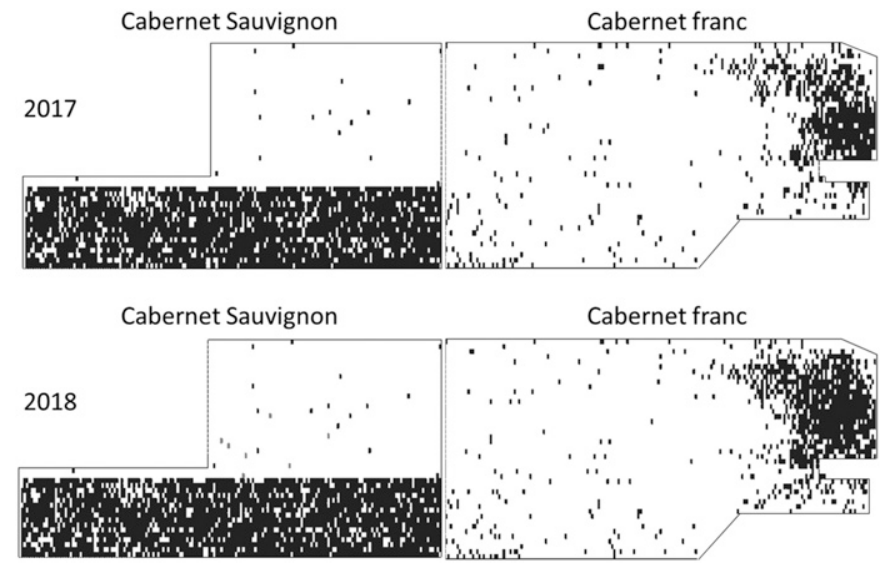

Fig. 2. Annual distribution of grapevine red blotch disease incidence (diseased vines indicated in black, healthy vines indicated by white space) in 2017 (top) and 2018 (bottom) in a 1.5-ha Cabernet Sauvignon vineyard and a 2.0-ha Cabernet franc vineyard in Rutherford, California. reddening symptoms. This estimate was validated by our own visual inspection of vines at a prevéraison development stage in 2013. Annual collection of leaf samples from $51 \mathrm{GRBV}$-infected and 14 GRBV-negative vines in the Merlot vineyard followed by PCR testing in 2014 to 2018 provided no indication of spread. All vines that tested negative in 2014 continued to test negative for GRBV through the 2018 season.

Genetic diversity of GRBV in infected grapevines. In the Cabernet Sauvignon vineyard in California, GRBV isolates from vines of clone 4 represented phylogenetic clades 1 and 2 (Fig. 3),

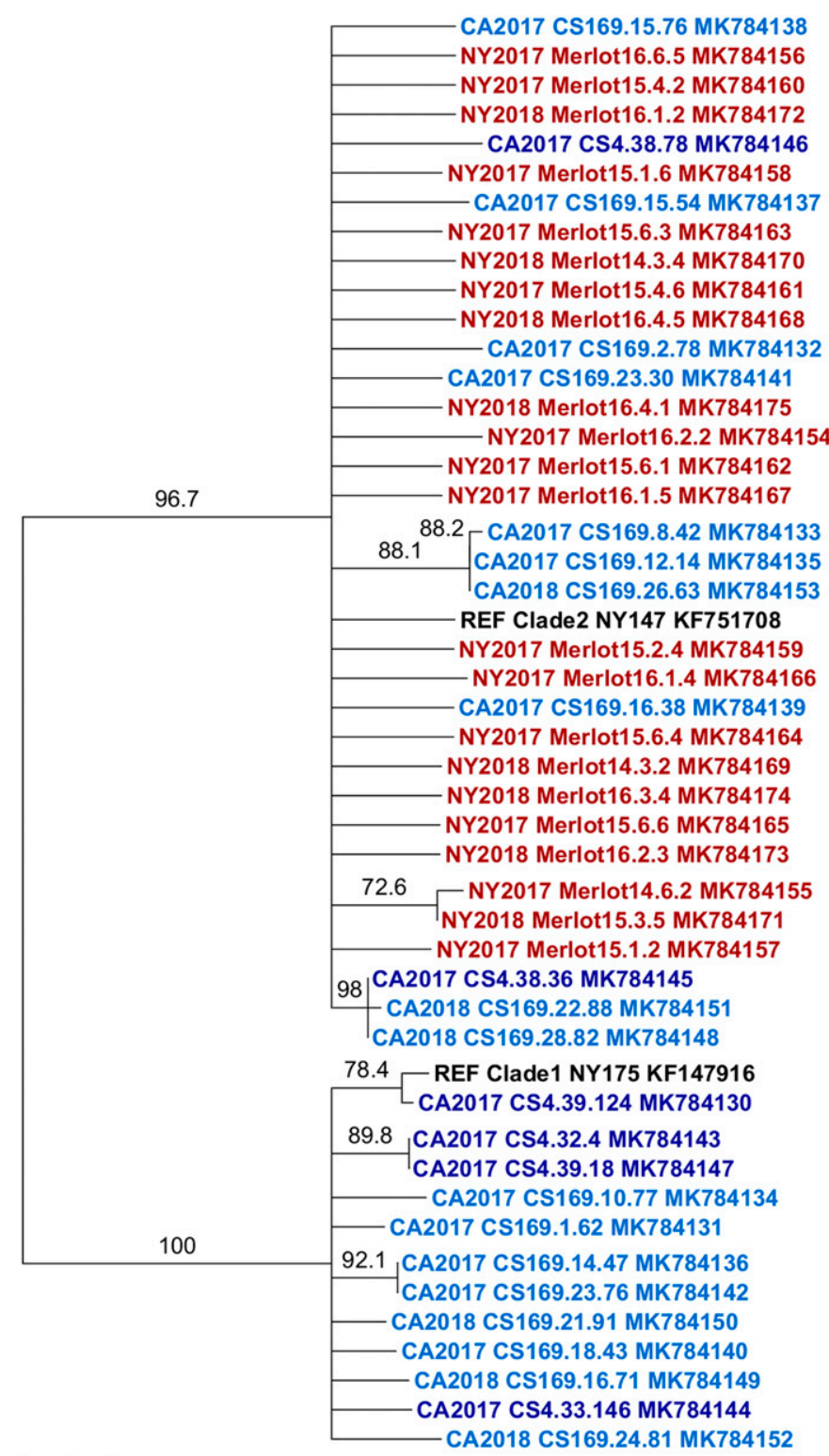

$0.0 \quad 0.006$

Fig. 3. Neighbor-joining phylogenetic tree of a 575-nt genomic fragment spanning the origin of replication of grapevine red blotch virus (GRBV) isolates from the Cabernet Sauvignon vineyard in California and the Merlot vineyard in New York. Labels with red text indicate GRBV isolates from the New York vineyard, those with blue text indicate isolates from the California vineyard, where the darker blue specifies isolates from vines of clone 4 and lighter blue specifies isolates from vines of clone 169. Reference isolates for each phylogenetic clade are indicated in black. Numbers at nodes indicate bootstrap support (1,000 replicates). Branches with less than $70 \%$ support have been collapsed. NCBI GenBank accession numbers are included in the terminal node labels. 
suggesting vines were infected with a mixture of both genetic variants of GRBV at the time of planting. In symptomatic vines of clone 169, GRBV isolates were similarly of both phylogenetic clades (Fig. 3). In the Merlot vineyard in New York, all GRBV isolates characterized from a subset of symptomatic vines were nearly identical to each other ( $>99 \%$ nucleotide sequence identity) and clustered in phylogenetic clade 2 (Fig. 3). This result supported the hypothesis that the vines were infected at planting, likely because they were derived from Merlot vine stocks infected with the same isolate (Fig. 3). In the Cabernet franc vineyard, GRBV isolates from vines in the area of initial disease aggregation were previously characterized and shown to be nearly identical to each other ( $>99 \%$ nucleotide sequence identity) and clustered in phylogenetic clade 2 (Cieniewicz et al. 2017b). This lack of genetic variability was consistent with the virus inoculum originating from the planting material and with the occurrence of spread from local sources (Cieniewicz et al. 2018b).

Insect community and GRBV ingestion in the Cabernet Sauvignon vineyard in California. Most hemipteran insects caught on sticky cards in the Cabernet Sauvignon vineyard in California belonged to the families Membracidae, Cicadellidae, Cixiidae, Delphacidae, Aphididae, Phylloxeridae, Miridae, and Lygaeidae (Table 1). Of interest, $S$. festinus was rarely captured in the Cabernet Sauvignon vineyard. Additionally, only two of three specimens tested positive for GRBV in 2017, while the two specimens in 2018 tested negative for GRBV (Table 1). Of the five $S$. festinus found over 2 years, one of the GRBV-positive specimens was found on the clone 4 side and one on the clone 169 side, whereas one of the GRBV-negative specimens was found on the clone 4 side and two of the GRBV-negative specimens were found on the clone 169 side (Supplementary Fig. S1). GRBV was also detected in previously identified vector candidates $O$. borealis and C. reductus but not in the single Melanoliarus sp. specimen (Table 1). A few specimens of other phloem-feeding insects, including Scaphytopius magdalensis, Empoasca spp., as well as some aphids and foliar phylloxera species, tested positive for GRBV (Table 1); however, none of these insects was considered a vector candidate due to the comparatively low rate of GRBV detection in the insects throughout the season, although we recognize that transmission assays are needed in the future to rule out any role as vectors.

The monthly relative abundance of $S$. festinus, O. borealis, C. reductus, and Melanoliarus sp. was similar between 2017 and 2018, although the population peak was shifted earlier in 2018 compared with 2017 (Fig. 4). S. festinus detection on sticky traps peaked in July 2017 and in June 2018; O. borealis was found in August 2017 and July 2018; C. reductus peaked in May and August 2017, and in May and July 2018; Melanoliarus sp. was not found in 2017 and only one specimen was found on sticky cards in June 2018 (Fig. 4). Total detection on yellow sticky cards over the 2 years was low for $S$. festinus, $O$. borealis, and Melanoliarus sp. with five, eight, and one specimen, respectively; while $C$. reductus populations totaled 110 specimens over the 2 years (Fig. 4).

Insect community and GRBV ingestion in the Merlot vineyard in New York. Most hemipteran insects caught on sticky cards in the Merlot vineyard in New York belonged to the families Membracidae, Cercopidae, Cicadellidae, Aleyrodidae, Aphididae,

TABLE 1

Grapevine red blotch virus (GRBV) detection in insects trapped on yellow sticky cards in a diseased Vitis vinifera 'Cabernet Sauvignon' vineyard in California in 2017 and 2018 in which limited spread of GRBV was observed

\begin{tabular}{|c|c|c|c|c|c|c|c|}
\hline \multirow[b]{3}{*}{ Family } & \multirow[b]{3}{*}{ Genus, species } & \multicolumn{6}{|c|}{ GRBV detection $^{\mathrm{a}}$} \\
\hline & & \multicolumn{2}{|c|}{2017} & \multicolumn{2}{|c|}{2018} & \multicolumn{2}{|c|}{ Cumulative } \\
\hline & & $n$ & $\%$ & $n$ & $\%$ & $n$ & $\%$ \\
\hline \multirow[t]{7}{*}{ Cicadellidae } & Colladonus reductus & $19 / 63$ & 30 & $2 / 21$ & 10 & $21 / 84$ & 25 \\
\hline & Osbornellus borealis & $4 / 6$ & 67 & $0 / 1$ & 0 & $5 / 7$ & 71 \\
\hline & Euscelis sp. & $0 / 7$ & 0 & $0 / 28$ & 0 & $0 / 35$ & 0 \\
\hline & Empoasca sp. & $0 / 18$ & 0 & $3 / 66$ & 5 & $3 / 84$ & 4 \\
\hline & Erythroneura variabilis & $0 / 25$ & 0 & $0 / 50$ & 0 & $0 / 75$ & 0 \\
\hline & Erythroneura elegantula & $0 / 15$ & 0 & $0 / 49$ & 0 & $0 / 64$ & 0 \\
\hline & Erythroneura ziczac & $0 / 2$ & 0 & - & - & $0 / 2$ & 0 \\
\hline Cixiidae & Melanoliarus sp. & - & na & $0 / 1$ & 0 & $0 / 1$ & 0 \\
\hline Aphididae & & $1 / 28$ & 4 & $2 / 67$ & 3 & $3 / 95$ & 3 \\
\hline Delphacidae & & $0 / 2$ & 0 & $0 / 2$ & 0 & $0 / 4$ & 0 \\
\hline Phylloxeridae & & $0 / 8$ & 0 & $3 / 31$ & 10 & $3 / 39$ & 8 \\
\hline Psylloidea & & $0 / 6$ & 0 & $0 / 26$ & 0 & $0 / 32$ & 0 \\
\hline Miridae & & $0 / 12$ & 0 & - & na & $0 / 12$ & 0 \\
\hline Lygaeidae & & $0 / 2$ & 0 & - & na & $0 / 2$ & 0 \\
\hline
\end{tabular}

a $n$ indicates the proportion of individual specimens in which GRBV was detected by polymerase chain reaction; - indicates that no specimen was tested in that year; and na, not applicable. 
Fulgoroidea, and Psylloidea (Table 2). Interestingly, S. festinus was not detected on any of the sticky cards in 2017 or 2018 but other species of Membracidae (Acutalis sp., Entylia sp., Campylenchia sp., and Stictocephala sp.) were found (Table 2). Additionally, none of the three vector candidates identified in the California vineyards (Cieniewicz et al. 2018b; this study) was found in the Merlot vineyard. Of the treehoppers, only Entylia sp. tested positive for GRBV: one of seven specimens in 2017; and 1 of 30 specimens in 2018 (Table 2). These rates of ingestion are extremely low; therefore, Entylia sp. was not considered as a vector candidate. Phloem-feeding insects caught on sticky card traps occasionally tested positive for GRBV, indicating ingestion of the virus while feeding on the vines (Table 2). However, none of them was considered a potential vector candidate due to the low rate of GRBV ingestion, although transmission assays are needed to verify this hypothesis.

GRBV absent from surveyed vineyard cover crop species in Napa County, California. Cover crop species in vineyard middle rows were surveyed for GRBV in 13 vineyards in Napa County, California. Surveys were carried out in spring 2016 to 2018. Based on visual assessment of red blotch disease, four of the surveyed vineyards were heavily ( $>80 \%$ ) symptomatic, three were moderately (10 to $50 \%$ ) symptomatic, one was mildly symptomatic $(<5 \%)$, one was a recently planted vineyard, and four were of unknown disease incidence. Two of the vineyards were near water sources $(<10 \mathrm{~m}$ away from a river or pond), and five of them were adjacent to forested habitat. In 2016 and 2017 cover crop species included only legumes such as fava beans (Vicia faba, $n=121$ ), purple vetch (Vicia americana, $n=106$ ), red and white clover (Trifolium spp., $n=67$ ), and field peas (Pisum sativum subsp. arvense, $n=27)$. In 2018 cover crops included the aforementioned species $(n=132)$ as well as mixed grasses (Poaceae, $n=23$ ) from nine of the vineyard sites. None of the 476 total cover crop samples from Napa County exhibited red blotch-like disease symptoms, and GRBV was not detected in any of them in 2016, 2017, and 2018.

\section{DISCUSSION}

In this study we characterized spread of GRBV in three red blotch diseased vineyards, two in California and one in New York, all planted in 2008. Distinct spread dynamics were documented in the three vineyards with an increase in disease incidence of 4.8, 0.13, and $0 \%$ in a 2-ha Cabernet franc vineyard in California, a 1.5-ha Cabernet Sauvignon vineyard in California, and a 1.2-ha Merlot vineyard in New York, respectively. The differential rate of annual disease increase was unrelated to the initial level of GRBV inoculum available. Indeed, a 40\% (Merlot vineyard in New York), 40\% (Cabernet Sauvignon vineyard in California) and 1\% (Cabernet franc vineyard in California) initial infection rate was estimated at the time the vineyards were established. These estimates were based on visual observations of disease symptoms 1 to 4 years post-planting. The highest increase of infected vines (1 to $4 \%$ annually) was observed in the Cabernet franc vineyard with the lowest virus inoculum at planting $(1 \%)$, and the lowest increase of infected vines ( 0 and $0.13 \%$ annually) in the Merlot and Cabernet Sauvignon vineyards, respectively, with the highest virus inoculum at planting (40\%).

We also described the relative abundance and GRBV ingestion rates of hemipteran insects in two of the three study vineyards. Our findings revealed distinct insect communities in a Cabernet Sauvignon vineyard in California (Table 1) and in a Merlot vineyard in New York (Table 2). Only Psylloidea, Aphididae, and some Cicadellidae (Empoasca sp., Erythroneura sp., Deltocephalus sp., and Xestocephalus sp.) were common between the two vineyard ecosystems. Extremely low populations of S. festinus, currently the only known insect vector of GRBV (Bahder et al. 2016b), were found on sticky cards in the Cabernet Sauvignon vineyard in California, and no S. festinus was found in the Merlot vineyard in New York. The other three vector candidates previously identified, i.e., O. borealis, C. reductus, and Melanoliarus sp. (Cieniewicz et al. 2018b), were found on sticky cards in the Cabernet Sauvignon vineyard in California but not in the Merlot vineyard in New York.

The low number of S. festinus in the Cabernet Sauvignon vineyard (this study) represented a 10-fold lower population compared with the Cabernet franc vineyard previously studied (Cieniewicz et al. 2018b). Similarly, the relative abundance of $O$. borealis (minus sixfold) and Melanoliarus sp. (minus 20-fold) was reduced in the Cabernet Sauvignon vineyard (this study) relative to the Cabernet franc vineyard (Cieniewicz et al. 2018b) while relative abundance was slightly increased for $C$. reductus

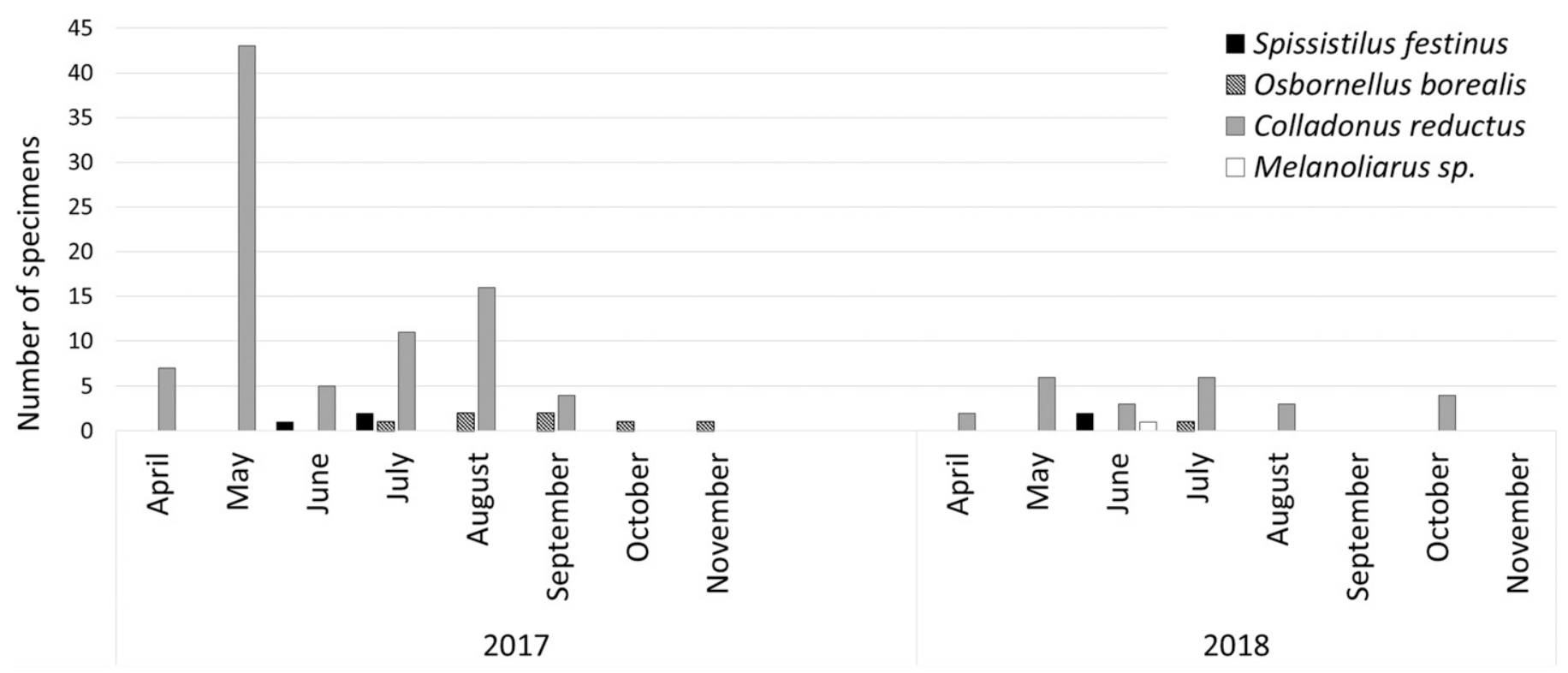

Fig. 4. Monthly relative abundance of Spissistilus festinus and candidate insect vectors trapped on yellow sticky cards in a Cabernet Sauvignon vineyard in Napa County, California in 2017 and 2018. 
(plus 1.3-fold). The Cabernet franc study was conducted in 2015 and 2016, and the Cabernet Sauvignon study in 2017 and 2018. Therefore, it is important to consider external factors, such as differences in weather and other environmental aspects, which may have contributed to the observed difference in S. festinus abundance between these two vineyards, although they are managed identically in terms of viticulture practices, pesticide application, and cover cropping. It is also interesting to note that the vineyard with a seemingly higher population of $S$. festinus is proximal to a riparian area surrounding the Napa River (Fig. 1). Knowing that S. festinus does not complete its reproductive cycle on Vitis sp. (Preto et al. 2018 b), it is possible that preferred plant hosts, from which $S$. festinus would migrate to the vineyard, are located in the wooded area. More work is needed to address this hypothesis.

The passive sampling method of yellow sticky cards may not be the ideal method of determining populations of insects (Cieniewicz et al. 2018b; Preto et al. 2019). This is because immature life stages of hemipterans and/or crawling insects are likely under-sampled and insects have varying levels of attraction to yellow sticky cards. Moreover, the populations of insects collected on sticky cards may not be representative of the entire insect community. Nonetheless, the sampling method of yellow sticky cards was a consistent form of sampling for comparison of relative abundance of flying insects between vineyards (Cieniewicz et al. 2018b; this study).

Secondary spread of GRBV has not been observed in New York, thus far (M. Fuchs, personal observation), although the virus is present in some vineyards in the Finger Lakes and Long Island regions (Krenz et al. 2014). The lack of spread of GRBV in a 5-year period (2014 to 2018) in the Merlot vineyard in the North Fork of Long Island, New York is consistent with the absence of $S$. festinus. The geographic range of $S$. festinus is throughout the southern United States and as far south as Costa Rica (Beyer et al. 2017; Caldwell 1949). To our knowledge, recent information on the geographic distribution of $S$. festinus in the United States is not available and this issue should be revisited, particularly with regard to changes in agricultural practices and climate change that occurred over the past 70 years. Despite the detection of four species of Membracidae on the sticky cards in the Merlot vineyard, only a single specimen each year of the Entylia species tested positive for GRBV. Using an arbitrary criteria of at least $30 \%$ of insects testing positive in a vineyard survey to be considered vector candidates (Cieniewicz et al. 2018b), we did not identify any insect vector candidates in the New York Merlot vineyard. The lack of observed secondary spread of GRBV in New York vineyards is also consistent with the absence of GRBV in free-living Vitis spp. throughout the state (Cieniewicz et al. 2018a). This is in contrast to the relatively high incidence of GRBV in free-living Vitis populations in northern California (Cieniewicz et al. 2018a).

Comparing the secondary spread dynamics of GRBV in the Cabernet franc (Cieniewicz et al. 2017b; this study) and the adjacent Cabernet Sauvignon (this study) vineyards in California demonstrated a marked difference, despite both vineyards being planted in

TABLE 2

Grapevine red blotch virus (GRBV) detection in insects trapped on yellow sticky cards in a diseased Vitis vinifera 'Merlot' vineyard in Suffolk County, New York in 2017 and 2018 in which no spread of GRBV was observed

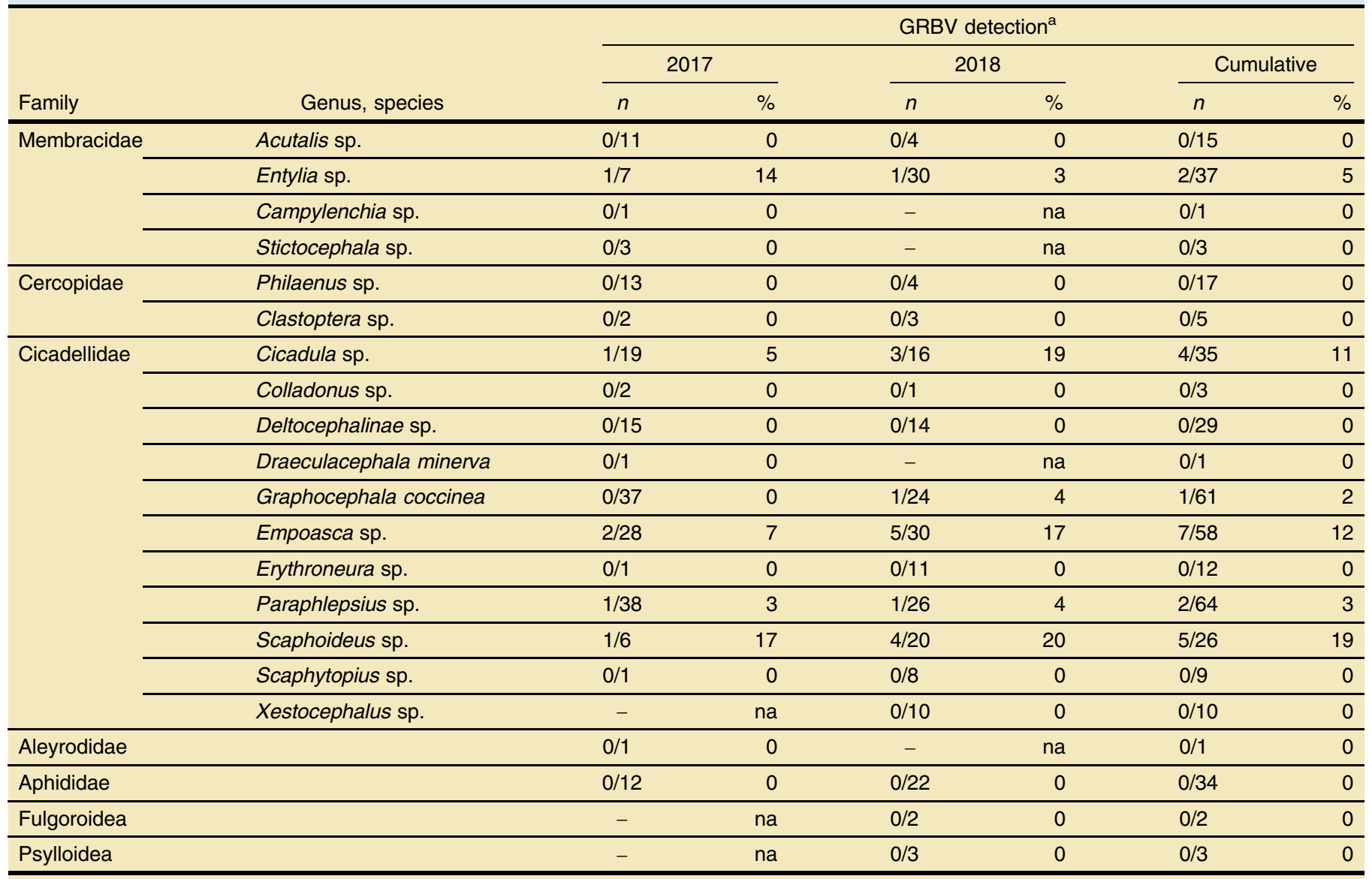

a $n$ indicates the proportion of individual specimens in which GRBV was detected by polymerase chain reaction; - indicates that no specimen was tested in that year; and na, not applicable. 
2008, and managed identically in terms of chemical practices against fungal diseases and cover crop rotations. Overall, secondary spread occurred faster in the Cabernet franc vineyard (1 to $4 \%$ increase annually) compared with the Cabernet Sauvignon vineyard ( $0.13 \%$ increase annually) despite the small initial source of inoculum in the former (estimated $1 \%$ at planting) and large source of initial inoculum in the latter (estimated $40 \%$ at planting) vineyard. We hypothesize this inverse spread dynamic could be attributable to the 10-fold higher population of $S$. festinus observed in the canopy of the Cabernet franc vineyard ( $n=25$ in each year) (Cieniewicz et al. 2018b) compared with the Cabernet Sauvignon vineyard ( $n=$ 2 to 3 in each year) (this study). Experiments under controlled conditions should be carried out to confirm observations made in diseased vineyards. Nonetheless, vineyard observations validated our hypothesis on the association between GRBV spread dynamics and abundance of $S$. festinus populations.

Spread dynamics of GRBV in the two study vineyards in California are similar to accounts of Pierce's disease (PD) outbreaks in California (reviewed by Redak et al. 2004). For example, in northern and coastal California, the blue-green sharpshooter (Graphocephala atropunctata) is associated with PD outbreaks near riparian habitats. Similarly, in vineyards in the Central Valley of California, PD outbreaks commonly occur near irrigated fields and water sources, even if the sharpshooter vectors are not colonizers of grape (Redak et al. 2004). Whereas Xylella fastidiosa, the causal agent of PD, can be transmitted from several plant hosts in these habitats, GRBV has thus far only been found in Vitis spp., and no other environmental reservoirs are known. Himalayan blackberry (Rubus armeniacus) was reported as an alternative host of GRBV in winter and spring in northern California (Bahder et al. 2016a); however, this finding has yet to be confirmed in independent studies. Free-living Vitis spp. near vineyards may serve as a source of GRBV inoculum for vector-mediated transmission to cultivated vines (Bahder et al. 2016b; Cieniewicz et al. 2018a; Perry et al. 2016). Nonetheless, free-living vines are likely a minor source of inoculum considering GRBV is widespread in vineyards in California (Krenz et al. 2014).

None of the vineyard middle-row cover crop species, including legumes, tested positive for GRBV over three consecutive years (2016 to 2018). This suggested that cover crops do not likely serve as major alternative GRBV inoculum source in a vineyard ecosystem, validating our hypothesis. We acknowledge that our surveys were not exhaustive and more efforts would be needed to definitely rule out the role of cover crops in the epidemiology of red blotch disease. In addition, although $S$. festinus can reproduce on Vitis spp., it does not complete its life cycle on this host (Preto et al. 2018a). Instead, S. festinus prefers to reproduce on hosts in the Fabaceae family (Preto et al. 2018b). This has profound implications for disease management. Preto et al. (2019) posit that $S$. festinus overwinter outside of vineyards and then reproduce in vineyard ground cover (cover crops or leguminous weeds), and feed on grapevine when the herbaceous groundcover dries up or is tilled. Additionally, higher levels of $S$. festinus aggregation were observed at the vineyard edge adjacent to an irrigation ditch (Preto et al. 2019). In our study, S. festinus populations in the vineyard canopy were reduced by 10 -fold at $250 \mathrm{~m}$ from the edge of the Napa River riparian habitat into the Cabernet Sauvignon vineyard (Fig. 1). This may be attributed to preferred hosts of S. festinus or a more suitable environment within the forested/riparian habitat. The significance of water sources to $S$. festinus phenology is unknown and should be further investigated.

Management practices to minimize spread of viruses by controlling insect populations are typically only effective when the insect vector is also a colonizer of the crop (Halbert 2008), which is not the case for S. festinus and Vitis spp. (Preto et al. 2018a). Moreover, depending on chemical control of vectors to control spread of viruses in perennial crops like grape is usually not warranted, as a single missed or suboptimal application can result in new virus infections (Halbert 2008). Therefore, although our study suggests that relatively higher $S$. festinus populations are potentially associated with faster rates of GRBV spread, our results taken together with behavioral studies of $S$. festinus (Preto et al. 2018a, b, 2019) reinforce recommendations that red blotch disease management efforts should focus on removing sources of virus inoculum rather than reducing populations of $S$. festinus. However, cultural controls to reduce $S$. festinus habitat may help in slowing spread if replanting is not desired in California.

\section{ACKNOWLEDGMENTS}

We thank F.-W. Choi for assistance with virus testing, A. Gardner for assistance with insect sticky cards in the Merlot vineyard in New York, A. Gorny and S. Pethybridge for statistical consultation, and G. Loeb for assistance with insect identification. We also are grateful to St. Supéry Estate Vineyards and Winery and One Woman Wines and Vineyards for supporting this research.

\section{LITERATURE CITED}

Al Rwahnih, M., Dave, A., Anderson, M. M., Rowhani, A., Uyemoto, J. K., and Sudarshana, M. R. 2013. Association of a DNA virus with grapevines affected by red blotch disease in California. Phytopathology 103:1069-1076.

Bahder, B. W., Zalom, F. G., Jayanth, M., and Sudarshana, M. R. 2016b. Phylogeny of geminivirus coat protein sequences and digital PCR aid in identifying Spissistilus festinus as a vector of grapevine red blotch-associated virus. Phytopathology 106:1223-1230.

Beyer, B. A., Srinivasan, R., Roberts, P. M., and Abney, M. R. 2017. Biology and management of the three-cornered alfalfa hopper (Hemiptera: Membracidae) in alfalfa, soybean, and peanut. J. Integr. Pest Manag. 8:1-10.

Bahder, B. W., Zalom, F. G., and Sudarshana, M. R. 2016a. An evaluation of the flora adjacent to wine grape vineyards for the presence of alternative host plants of grapevine red blotch-associated virus. Plant Dis. 100:1571-1574.

Blanco-Ulate, B., Hopfer, H., Figueroa-Balderas, R., Ye, Z., Rivero, R. M., Albacete, A., Pérez-Alfocea, F., Koyama, R., Anderson, M. M., and Smith, R. J. 2017. Red blotch disease alters grape berry development and metabolism by interfering with the transcriptional and hormonal regulation of ripening. J. Exp. Bot. 68:1225-1238.

Caldwell, J. S. 1949. A generic revision of the treehoppers of the tribe Ceresini in America north of Mexico based on a study of the male genitalia. Proc. U.S. Natl. Mus. 98:491-521.

Calvi, B. L. 2011. Effects of red-leaf disease on Cabernet Sauvignon at the Oakville experimental vineyard and mitigation by harvest delay and crop adjustment. M.S. thesis, University of California, Davis.

Cieniewicz, E., Perry, K., and Fuchs, M. 2017a. Grapevine Viruses: Molecular Biology, Diagnostics and Management. Pages 303-314 in: Grapevine Viruses: Molecular Biology, Diagnostics and Management. B. Meng, G. Martelli, D. Golino, and M. Fuchs, eds. Springer Verlag, Berlin, Germany. Cieniewicz, E., Thompson, J. R., McLane, H., Perry, K. L., Dangl, G. S., Corbett, Q., Martinson, T., Wise, A., Wallis, A., O'Connell, J., Dunst, R., Cox, K., and Fuchs, M. 2018a. Prevalence and genetic diversity of grabloviruses in free-living Vitis spp. Plant Dis. 102:2308-2316.

Cieniewicz, E. J., Pethybridge, S. J., Gorny, A., Madden, L. V., McLane, H., Perry, K. L., and Fuchs, M. 2017b. Spatiotemporal spread of grapevine red blotch-associated virus in a California vineyard. Virus Res. 241:156-162.

Cieniewicz, E. J., Pethybridge, S. J., Loeb, G., Perry, K., and Fuchs, M. 2018b. Insights into the ecology of grapevine red blotch virus in a diseased vineyard. Phytopathology 108:94-102.

Dalton, D. T., Hilton, R. J., Kaiser, C., Daane, K. M., Sudarshana, M. R., Vo, J., Zalom, F. G., Buser, J. Z., and Walton, V. M. 2019. Spatial associations of vines infected with grapevine red blotch virus in Oregon vineyards. Plant Dis. 103:1507-1514.

Gasperin-Bulbarela, J., Licea-Navarro, A. F., Pino-Villar, C., HernándezMartínez, R., and Carrillo-Tripp, J. 2019. First report of grapevine red blotch virus in Mexico. Plant Dis. 103:381. 
Halbert, S. 2008. Management of insect-vectored pathogens of plants. Pages 1336-1337 in: Encyclopedia of Entomology, 2nd ed. J. L. Capinera, ed. Springer, Netherlands.

Holzinger, W. E., Emeljanov, A. F., and Kammerlander, I. 2002. The family Cixiidae (Spinola) 1839 (Hemiptera: Fulgoromorpha)_A review. Denisia 4:113-138.

Jensen, D. D. 1957. Transmission of peach yellow leaf roll virus by Fieberiella florii and a new vector, Osbornellus borealis. J. Econ. Entomol. 50:668-672.

Krenz, B., Thompson, J. R., Fuchs, M., and Perry, K. L. 2012. Complete genome sequence of a new circular DNA virus from grapevine. J. Virol. 86:7715.

Krenz, B., Thompson, J. R., McLane, H., Fuchs, M., and Perry, K. L. 2014. Grapevine red blotch-associated virus is widespread in the United States. Phytopathology 104:1232-1240.

Lim, S., Igori, D., Zhao, F., Moon, J. S., Cho, I.-S., and Choi, G.-S. 2016. First report of grapevine red blotch-associated virus on grapevine in Korea. Plant Dis. 100:1957.

Luna, F., Debat, H., Moyano, S., Zavallo, D., Asurmendi, S., and GomezTalquenca, S. 2019. First report of grapevine red blotch virus infecting grapevine in Argentina. J. Plant Pathol. doi.org/10.1007/s42161-019-00298-3

Martínez-Lüscher, J., Brillante, L., Yu, R., Plank, C., Smith, R. J., Cooper, M., Oberholster, A., and Kurtural, K. 2019. Grapevine red blotch virus may reduce carbon translocation leading to impaired grape berry ripening. J. Agric. Food Chem. 67:2437-2448.

Marwal, A., Kumer, R., Khurana, S. M. P., and Gaur, R. K. 2019. Complete nucleotide sequence of a new geminivirus isolated from Vitis vinifera in India: A symptomless host of grapevine red blotch virus. Virus Dis. 30:106-111.

Mueller, A. J., and Dumas, B. A. 1975. Effects of stem girdling by the threecornered alfalfa hopper on soybean yields. J. Econ. Entomol. 68:511-512.

Perry, K. L., McLane, H., Hyder, M. Z., Dangl, G. S., Thompson, J. R., and Fuchs, M. F. 2016. Grapevine red blotch-associated virus is present in free-living Vitis sp. proximal to cultivated grapevines. Phytopathology 106:663-670.

Poojari, S., Lowery, D. T., Rott, M., Schmidt, A. M., and Úrbez-Torres, J. R. 2017. Incidence, distribution and genetic diversity of grapevine red blotch virus in British Columbia. Can. J. Plant Pathol. 39:201-211.

Preto, C. R., Bahder, B. W., Bick, E. N., Sudarshana, M. R., and Zalom, F. G. 2019. Seasonal dynamics of Spissistilus festinus (Hemiptera: Membracidae) in a Californian vineyard. J. Econ. Entomol. 112:1138-1144.

Preto, C. R., Sudarshana, M. R., Bollinger, M. L., and Zalom, F. G. 2018b. Vitis vinifera (Vitales: Vitaceae) as a reproductive host of Spissistilus festinus (Hemiptera: Membracidae). J. Insect Sci. 18:1-7.
Preto, C. R., Sudarshana, M. R., and Zalom, F. G. 2018a. Feeding and reproductive hosts of Spissistilus festinus (Say) (Hemiptera: Membracidae) found in Californian vineyards. J. Econ. Entomol. 111:2531-2535.

Redak, R. A., Purcell, A. H., Lopes, J. R. S., Blua, M. J., Mizell, R. F., III, and Andersen, P. C. 2004. The biology of xylem fluid-feeding insect vectors of Xylella fastidiosa and their relation to disease epidemiology. Annu. Rev. Entomol. 49:243-270.

Reynard, J. S., Brodard, J., Dubuis, N., Zufferey, V., Schumpp, O., Schaerer, S., and Gugerli, P. 2018. Grapevine red blotch virus: Absence in Swiss vineyards and analysis of potential detrimental effect on viticultural performance. Plant Dis. 102:651-655.

Ricketts, K. D., Gómez, M. I., Fuchs, M. F., Martinson, T. E., Smith, R. J., Cooper, M. L., Moyer, M. M., and Wise, A. 2017. Mitigating the economic impact of grapevine red blotch: Optimizing disease management strategies in U.S. vineyards. Am. J. Enol. Vitic. 68:127-135.

Saitou, N., and Nei, M. 1987. The neighbor-joining method: A new method for reconstructing phylogenetic trees. Mol. Biol. Evol. 4:406-425.

Thompson, J. D., Higgins, D. G., and Gibson, T. J. 1994. CLUSTAL W: Improving the sensitivity of progressive multiple sequence alignment through sequence weighting, position-specific gap penalties and weight matrix choice. Nucleic Acids Res. 122:4673-4680.

Vargas-Asencio, J., Liou, H., Perry, K. L., and Thompson, J. R. 2019. Evidence for the splicing of grablovirus transcripts reveals a putative novel open reading frame. J. Gen. Virol. 100:709-720.

Varsani, A., Roumagnac, P., Fuchs, M., Navas-Castillo, J., Moriones, E., Idris, A., Briddon, R. W., Rivera-Bustamante, R., Murilo Zerbini, F., and Martin, D. P. 2017. Capulavirus and Grablovirus: Two new genera in the family Geminiviridae. Arch. Virol. 162:1819-1831.

Wolfe, H. R. 1955. Transmission of the Western X disease virus by the leafhopper Colladonus montanus (Van D.). Plant Dis. Rep. 39:298-299.

Wolfe, H. R., Anthon, E. W., and Jones, S. L. 1950. Transmission of western Xdisease of peaches by the leafhopper Colladonus geminatus (Van D.). (Abstr.) Phytopathology 40:971.

Xiao, H., Kim, W. S., and Meng, B. 2015. A highly effective and versatile technology for the isolation of RNAs from grapevines and other woody perennials for use in virus diagnostics. Virol. J. 12:1-15.

Yepes, L. M., Cieniewicz, E. J., Krenz, B., McLane, H., Thompson, J. R., Perry, K. L., and Fuchs, M. 2018. Causative role of grapevine red blotch virus in red blotch disease. Phytopathology 108:902-909. 